\title{
The Social Capital of Broiler Farmers in a Partnership System in Blitar, Indonesia
}

\author{
Indah Wulandari ${ }^{1}$, Mahendra Wijaya ${ }^{2}$, and Ahmad Zuber ${ }^{3}$ \\ Postgraduate of Sociology, Universitas Sebelas Maret Surakarta, Indonesia ${ }^{1}$ \\ Department of Sociology, Faculty of Social and Political ScienceUniversitas Sebelas Maret \\ Surakarta, Indonesia ${ }^{2,3}$ \\ \{indah.wulandari999@gmail.com ${ }^{1}$, a.zuber@uns.ac.id $\left.{ }^{3}\right\}$
}

\begin{abstract}
The broiler farming in partnership system is not only about getting a lot of profit but also how to maintain partnershipsto keep thebusiness.Basically broiler farming in partnership system formed because of the mutual need between farmers and partner companies. Usually, farmers who choose a partnership system because they have limited capital and they want low risk while the partner companies have limited area and worker. This qualitative research was conducted in Blitar Regency which became one of broiler farming centers in Indonesia. This paper discusses how the social capital of farmers contributes to the sustainability of the partnership. The result showed that farmers and partner companies started a business based on trust between them. When one of the parties break the rules and belief became destroyed then the partnership will be threatened. If the social network is secure and visible from the interchange among members, then business will be maintained. So the social capital of farmers makes a positive contribution to support the sustainability of partnership.
\end{abstract}

Keywords: Social Capital, Broiler Farmers, Partnership

\section{Introduction}

Poultry farming business in Indonesia is currently experiencing rapid growth. Poultry farming can be an alternative to reduce unemployment. In February 2017 a number of unemployment rate more than 7.01 million people (5.3 percent of the total population of Indonesia). Broiler Chicken is one type of commodity in the field of animal husbandry that produces nutrition and has a potential economic value. Broiler meat dominates the amount of livestock production in Indonesia. In 2016, amount of broiler meat prodution more than 1.62 million tons [1]. There are two types of broiler farming are independent and partnership system. Broiler farming in partnership system is more desirable of the community in Indonesia compared with raising independently especially for farmers who have limited capital. Independently farming is considered to have a higher risk, especially when financial losses. Especially after the economic crisis in 1998 many independent farmers who move following in the partnership system. About 70 percent of national broiler production is produced by farmers of partnership systems. One of the areas that support the national meat production is Blitar Regency which in 2015 produces 60,900 tons of broiler meat [2]. 
Partnership is the relation which is the subsist of a person carrying on a business in common with a view of profit [3]. The partnership must apply the principle of equality so that no one will feel disadvantaged.Contracts that have been agreed together before making a partnership is not just a formality because it will be influenced to the sustainability of the partnership.Although both farmers and partner companies want a profit but the ethics in doing the partnership must be maintained.The success of the business in a partnership system depends on the businessman in maintaining business ethics to achieve the same goal of gaining profit. This neglect of social aspect may adversely affect the partnership. Therefore, the author tries to see the continuity of partnership related to the social capital of farmers.

There are several relevant research related to this paper among others which have the theme of broiler farming in partnership system or used the concept of social capital. Like that researchrevealed that the three elements of social capital namely trust, networks and institutions important in increasing the production of coffee crops. Trust will build a critical awareness of farmers to do collective work by utilizing new technologies. The network that exists between farmers and traders for a long time makes traders willing to accept coffee under any circumstances even though it is still logged. While the third aspect of the institution includes the intermediary becomes the most responsible for the economic behavior of coffee farmers [4]. Other research showed that the most influential variables on the price of poultry is the weight of poultry and feed conversion ratio. The issue of feed conversion ratio usually occurs because the feed is provided by unofficial companies, wrong in the use of technology, careless in maintenance, cleanliness and stable, lack of knowledge about feed standards, or feeding too much [5]. The average farmer earns a profit that when compared to the Minimum Wage Regional (UMR) in the research area gained profits are quite satisfactory [6].

According to some existing research with the theme of broiler farming in partnership system mostly focuses on how the technical farming starts from seed selection, feeding, marketing or calculating the profit and loss of the business. There has been limited studied see how to maintain the partnership. The fact is broiler farming in partnership system not only about getting a lot of profit but also how to maintain partnershipsto keep thebusiness. There are some problems faced by farmers about partner companies. Refers to the method, there are few studies usingthe qualitative approach with case study strategy to see broiler farming in partnership system. Most research used a quantitative approach with survey methods. While it refers to the theory, there has been limited studied to see broiler farming in partnership system with the concept of social capital. So this research is interesting because trying to see how the social capital of farmers contributes to the sustainability of the partnership. It's mean that this research is trying to see broiler farming with different analysis (sociological analysis) than much other research with financial analysis or animal farm science.

\section{Method}

This research uses the qualitative approach with case study strategy. Qualitative research thus refers to the meanings, concepts, definitions, characteristics, metaphors, symbols, and descriptions of things [7]. The reason for choosing qualitative approaches to explain the case more deeply. Qualitative case studies as research using empirical evidence from one or more organizations and researchers try to learn the problem from the context [8]. Case study research dividedinto three types that is explanatory, exploratory, and descriptive [9]. This study uses an explanatory case study with the consideration that explanatory case studies will be useful when used in cause-and-effect studies, especially in complex societal or 
organizational research, want consideration for using a variety of cases to test some of the effects.

The research location of Blitar Regency because it is one of broiler farming center of the partnership system in Indonesia so that it is considered has enough data availability. The study was conducted for three months from July to September 2017. Data collection through indepth interviews, observation, and documentation. Interviews were conducted with ten broiler farmers in partnership system, three from partner companies and several supporting informants such as workers in farms, collectors and government officials related to the farm. While the selection of informants using purposive sampling technique with maximum variation. The maximum variation sampling strategy to capture or represent a central theme of the study through cross-cutting information by selecting informants with different characteristics. Farmers selected to be informants are classified as successful or less successful. To validity of data used triangulation of sources and method. While the data analysis used interactive analysis technique which includes data collection, reduction, data presentation, and conclusion [10].

\section{Result and discussion}

Implementation of the partnership system that farmers provide cages, equipment, and labor While the companies provide starting from seeds, feed, medicines as well as the direction in livestock management to get satisfactory results or profit. At the location of the research, the partnership system used the price contract system. In this price contract system, there is already an agreement at the beginning about the risk of loss. Production input prices and selling prices are determined by the partner companies, and usually, the farmer must submit securities as collateral and sign the agreement. Although in the partnership system there are already agreements in the implementation, there are still some problems especially felt by the farmers such as delayed delivery of feed and medicines, late payment of crop, and have a low bargaining position.

Social capital similar to the notions of physical and human capital refers to features of social organization, such as network, norms, and trust that increase a society's productive potential [11]. While other definition says that the sum of the resources, actual or virtual, that accrue to an individual or a group by possessing a durable network of more or less institutionalized relationships of mutual acquaintance and recognition[12], in a rural community, networking which strengthens social capital will facilitate the outer channel and ideas to stimulate the development of community groups, mutual help culture, so as to reflect the spirit of reciprocity, trust and social networking [13].According to this definition concludes that the important element of social capital is trust, norm, networking,and reciprocity.

The main element of social capital formers is the existence of trust among members. Trust may be defined as confidence in the reliability of a person or system, regarding a given set of outcomes or events, where that confidence express a faith in the probity or love of another, or the correctness of abstract principles (technical knowledge) [14]. In the business context of trust can be seen in three forms of competence trust, contractual trust, and good faith belief[15]. Competency trust refers to the belief that the business partner will perform the obligation by the ability or competence. While contractual trust is the belief that the business partner will keep the agreement or contract that has been agreed upon. Meanwhile, the faith of goodwill refers to the same hope between the two parties in an open relationship to achieve common goals and benefit. 
The partnership system can take place when there is trust between farmers and partner companies. Before signing a partnership contract usually, the partner companies represented by "Petugas Penyuluh Lapangan" (PPL) or Field Extension Officers will first check how the feasibility of preparation by farmers. Some things are seen like the feasibility of the cage and all the equipment needed. Also, the company will ask about the experience in farming to find out how the competence of farmers who will become their partners. Partnerships may end when there is no trust between the partners. This is especially true when there are often delays in feed supply or harvest payments by a company that result in the termination of partnership by farmers. Some of the cases that researchers found as the cause of the end of the partnership are the existence of contractual violations by both partner companies and farmers. For example,there are farmers who sell chickens that are before the harvest without the knowledge of the partner company. Indeed when the yield above the target set, the remaining chicken is the right of the farmers. But it also obtained farmers after the harvest is over. Especially if farmers sell chickens in large quantities so that when the harvest does not reach the target. If the farmers "steal" the chicken before the harvest, the company does not hesitate to break the partnership because it is detrimental to the company.

Maintaining trust between the partners is very important especially for the farmers because they have limited capital,so they need a partner company to keep running their business. If their track record is bad, it will be difficult to find a partner company willing to cooperate. Also, the belief in PPL also greatly determines the sustainability of the partnership. PPL is a bridge between farmers and partner company so that when they do not become good bridges, then the partnership relationship will be in danger of being destroyed. The trust of the farmers to the partner company depends on how the PPL acts in the field. There has been the case of many farmers who decide on a partnership with a company when under the same PPL supervision because the farmer feels that the PPL is only seeking personal gain and harming the farmer for not being transparent.

The existence of the norm also determines how trust will be established between farmers and partner companies. Norm is specified what actions are regarded by a set of persons as proper or correct, or improper and incorrect[16]. Social norms have consequences meaning disobedience to norms or behaviors that are not by the norms that apply to cause a person subject to sanctions. In the context of sanctioned partnership system can be a termination of the partnership relationship. Farmers reveal that to maintain the trust of partner companies against their competence is to keep honest and disciplined even though the company does not at all times sees what they do. It means that the norms in the partnership system are not only written contracts but also unwritten ones, such as upholding the principle of partnership. Partnership system has several basic principles, among others (1) Equality or balance, the implementation used is not top down or bottom up, but the relationship of mutual respect and mutual trust between parties so that there is no dominance of either party and create equality that includes the existence of rewards, obligations, and bonds. (2) Transparency, which is necessary to avoid suspicion among partners. Transparency includes information management and financial management. (3) Mutually beneficial, that a partnership should bring benefits to all parties involved. If you want the partnership to run well, then both parties must comply with all norms and uphold the principle of partnership to get maximum results.

Social networks are a set of specific or specific relationships formed between a group of people whose characteristics these relationships can be used to interpret the motives of the social behavior of the people involved[17]. The existence of social networks in society and norm will encourage productivity of the community. The meaning of the horizontalassociationnot only gives a desirable outcome but also undesirable outcome 
(additional result) [18]. The strength or weakness of a social network is determined by the trust among its members in this case between the farmers, partner companies, PPL, and the chicken collectors who buy the crop. This social network is very important to be able to advance the partnership system because when the social network is strong and broad, then the knowledge gained will be more as well. As most farmers can follow the partnership system because it is suggested by the loan farmers who has previously partnered with the companies. When a company has a good name, then the farmer's trust level to join is also higher. So both farmers and partner company have no trouble getting business partners. Especially before they already know how prospective business partners in running partnerships of social networks owned. This is where the importance of maintaining good quality from farmers and partner companies because of good or bad quality they will be known by the social network and will affect the business forward. The worst of possibilities for example when the partnership with partner companies ends, farmers cand find other partner companies from their social network.

Meanwhile, reciprocity can be found in the form of giving, mutual acceptance and mutual help that can arise from social interaction. Social capital is always characterized by a tendency to exchange goodness among individuals who are part or members of the network. This reciprocal relationship can also be assumed as complementary and mutually supportive of one another. In this partnership, reciprocity can be seen for example when the partner company provides seminars for the breeders to be able to increase productivity. This is important for both parties because when the productivity of farmers increases then the profits of the company will also increase. Farmers are happy when they are given seminars like this because in addition to getting new knowledge on how to raise a good they also feel noticed by partner companies. When farmers feel paid attention to the company they claim will improve the quality so that the company is satisfied with its performance. Also, for example, when farmers do not get the maximum results when the harvest is usually the company is still providing compensation for operational costs. There are also cases experienced by farmers when their cages are damaged by "putingbeliung". They get help from the company even though the amount is not so much,but it is a form of attention as a business partner. To provide highermorale, the company will also provide market bonuses for farmers that exceed the target when prices are on the high market. Things like that can strengthen relationships in partnerships because they help each other and strengthen.

Thus social capital has a relationship with the sustainability of the partnership system. If the social capital is weak, then the partnership will be in danger of being destroyed but vice versa if the social capital is strong then the partnership will go well. In addition, social capital is also in line with the principle of partnership such as the principle of transparency with regard to trust in social capital. If the partnership is less transparent, then the trust in it will also be low. The principle of mutual benefit relates to reciprocity in social capital.

Social capital also can be one solution tothe problem faced by farmers relating to the partnership system. For example, when there is a delay in the delivery of feed or medicines required farmers tend to borrow to other farmers either partnered with the same company or not. It means they take advantage of the social network they have to meet their needs. In addition, when mutual borrowing is already a natural thing among the farmers then also showed the existence of reciprocity. While the low bargaining position of farmers compared to partner companies will not be so felt when there are mutual relationships mutually beneficial among parties who partner. So social capital also plays a role to overcome the problem of low bargaining power. 


\section{Conclusion}

The social capital of farmers has an important contribution to the sustainability of the partnership. The establishment of partnership because of the trust between farmers and partner companies. Trust built of how the compliance norms of members in the partnership and also manifested in mutual relations between them. If social capital of farmers are strong so the sustainability of partnership will then to be longer. Moreover when the partnership end, social capital still have a contribution to farmers because they can find the new partner companies based on information from their social networking. Social capital also can be one solution tothe problem faced by farmers relating to the partnership system.

\section{References}

[1] Dirjennak, Animal Husbandry,and Animal Health Statistics. Jakarta: General Directorate of Animal Husbandry and Animal Health, 2016.

[2] Disnakkan, Lakip (Performance Accountability Report of Government Agencies). Blitar: Livestock Service Office of Blitar Regency, 2015.

[3] K. L. Fletcher, The Law of Partnership. Sidney: The Law Book Company Limited, 1987.

[4] Heliawaty, M. S., Salman, A. S. D., and J. Rahman Mappangaja, "Social Capital And Economic Behavior Of Farmers International," Int. J. Sci. Technol. Res., vol. 4, no. 1, pp. 89-91, 2015.

[5] R. B. Majid and S. Hassan, "Performance of broiler contract farmers: A case study in Perak, Malaysia," in UMK Procedia, 2014, vol. 1, pp. 18-25.

[6] S. Nurtini, M. A. U. Muzayyanah, F. T. Haryadi, and A. Hakim, "Performance of Broiler Farmer In Patnerships System At Surakarta Indonesia," J. Adv. Agric. Technol., vol. 4, no. 2, pp. 196-199, 2017.

[7] B. L. Berg, Qualitative Research Methods for Social Sciences. Boston: Pearson Publications, 2007.

[8] M. Myers, Qualitative Research In Business \& Management. London: Sage Publications, 2009.

[9] R. K. Yin, Case Study Research: Design and Methodss. London: Sage Publications, 2013.

[10] M. B. Miles, A. M. Huberman, and J. Saldana, Qualitative Data Analysis. London: Sage Publications, 2013.

[11] Putnam R D, "The Prosperous Community: Social Capital and Public," Life Am. Prospect, vol. 13, pp. 35-41, 1993.

[12] P. Bourdieu and L. Wacquant, An Invitation To Reflexive Sociology. Chicago: University of Chicago Press, 1992.

[13] J. Hasbullah, Social Capital: Toward The Excellence of Indonesian Culture. Jakarta: MR-United Press, 2006.

[14] A. Gidden, The Consequences of Modernity. Stanford University Press, 1990.

[15] M. Sako, Price Quality and Trust : Inter-firm Relations Britain and Japan. Cambridge: Cambridge University Press, 1992.

[16] J. Coleman, Foundations of Social Theory. Cambridge: Harvard University Press, 1990.

[17] J. C. Mitchell, The Concept and Use of Social Network. Manchester: University of 
Manchester Press, 1969.

[18] R. D. Putnam, "Bowling Alone: America's Declining Social Capital," in Culture and Politics, vol. 6, New York: Palgrave Macmillan US, 2000, pp. 223-234. 